Journal of Applied Pharmaceutical Science Vol. 7 (06), pp. 121-126, June, 2017

Available online at http://www.japsonline.com

DOI: $10.7324 / \mathrm{JAPS} .2017 .70616$

ISSN 2231-3354 (cc)) BY-NC-SA

\title{
Comparative Evaluation of Metronidazole Suspensions Formulated with Raphia africana Hydrocolloid and other Natural Polymers
}

\author{
Musiliu O. Adedokun", Emmanuel O. Olorunsola, Edidiong L. Anselem \\ Department of Pharmacuetics and Pharmacuetical Technology, Faculty of Pharmacy, University of Uyo, Uyo. Akwa Ibom State, Nigeria.
}

\begin{tabular}{|c|c|}
\hline ARTICLE INFO & ABSTRACT \\
\hline $\begin{array}{l}\text { Article history: } \\
\text { Received on: } 17 / 01 / 2017 \\
\text { Accepted on: } 28 / 02 / 2017 \\
\text { Available online: } 30 / 06 / 2017\end{array}$ & $\begin{array}{l}\text { The suspending properties of Raphia africana hydrocolloid were assessed comparatively with some natural } \\
\text { polymers - compound tragacanth powder, acacia gum and gelatin in metronidazole suspension formulations. } \\
\text { The gum was extracted from the exudates of } R \text {. africana palm, and then characterized. Different batches of } \\
\text { metronidazole suspension were prepared using the polymers at } 0.5-4.0 \% \mathrm{w} / \mathrm{w} \text { concentrations. Various }\end{array}$ \\
\hline $\begin{array}{l}\text { Key words: } \\
\text { Raphia africana } \\
\text { hydrocolloid; sedimentation } \\
\text { volume; redispersibility } \\
\text { number; viscosity; } \\
\text { metronidazole suspension. }\end{array}$ & $\begin{array}{l}\text { particle size for all the polymers were evaluated comparatively. It was discovered that their suspending ability } \\
\text { was in the order of } R \text {. africana gum }>\text { compound tragacanth }>\text { acacia }>\text { gelatin. Generally, the higher the } \\
\text { concentration of these polymers, the higher the sedimentation volume, redispersibility number, viscosity, degree } \\
\text { of flocculation and particle size, and vice versa for the flow rate. From statistical analysis using SPSS statistical } \\
\text { package, } R \text {. africana gum exhibited significantly higher sedimentation volume, viscosity and flocculation } \\
\text { (p<0.05), and lower flow rate ( }<0.05 \text { ) than other tested materials. The results suggest that } R \text {. africana gum has } \\
\text { strongest and best suspending properties of all the investigated natural polymers at all employed concentrations } \\
\text { and thus has good potential as a novel suspendant in pharmaceutical suspensions. }\end{array}$ \\
\hline
\end{tabular}

\section{INTRODUCTION}

Suspension, a liquid dosage delivery system is a convenient way to administer insoluble or sparingly soluble drugs to paediatric and geriatric patients that have difficulty in swallowing tablets or capsules. It is employed to mask taste and to control absorption rate of the drug. Moreover, drugs so formulated exhibit higher bioavailability than those in solid dosage delivery systems (Adikwu et al., 2003; Ali et al., 2010; Edaga et al., 2014). However, a major challenge in the formulation of oral suspension is that of physical stability (Eraga et al., 2014): On storage, the solid insoluble drug separates from the vehicle and settles to the bottom of the container. It is desirable that such formulations re-disperse easily upon shaking

* Corresponding Author

Musiliu O. Adedokun, Department of Pharmacuetics and

Pharmacuetical Technology, Faculty of Pharmacy, University of Uyo,

Uyo. Akwa Ibom State, Nigeria.Email; mo_adedokun @ yahoo.com
(Ansel, 2005). This thus informs the essence of incorporating suspending agents especially hydrocolloids (gums) into suspension formulations.

Hydrocolloids are colloidal polymers which are utilized not only as adjuvants in liquid dosage forms like suspensions, but also extensively in many others including solid and semisolid formulations (Mahmud et al., 2009; Olorunsola and Adedokun, 2014). As suspending agents, they act by adsorption on the water insoluble particles keeping them dispersed within the dispersion medium (Olorunsola et al., 2014). They also increase the viscosity and density of the medium thereby retarding the settling of the particles (Olorunsola and Adedokun, 2014).

Raphia hydrocolloid is the exudates obtained from Raphia palm (family Arecaceae / Palmae). The genus is hapazanthic in nature; in other words, after a vegetative growth period, it yields flowers and fruits only once and dies (Obahiagbon, 2009). It comprises of about twenty species of palms native to tropical African region. One species, $R$. taedigera however, is also 
found in Central and South America. R. africana grows in dense forest but is also cultivated in swampy areas as well as on dry land (Otedoh, 1982).

Although, $R$. africana gum has been studied as a binder in paracetamol tablet formulations (Majekodunmi and Itiola, 2016), it seems that no known work has been reported on the suspending properties of this gum especially in comparison with already established commercial suspending agents. The relative abundance and wide distribution of $R$. africana palm and the cheapness, non-toxicity, biocompatibility and biodegradability of its gum had prompted us to investigate this hydrocolloid as suspending agent and to comparatively assess it with compound tragacanth gum, acacia gum and gelatin in metronidazole suspensions. Metronidazole, an anti-infective agent which has specific activity against a number of obligate anaerobic organisms and protozoa (Stanley 2003; Nash, 2001) was employed as a model drug due its poor aqueous solubility (The United States Pharmacopoeia, USP, 2014).

\section{MATERIALS AND METHODS}

\section{Materials}

The materials used were Metronidazole in fine powder (BDH Chemicals Ltd Poole, England), Acacia gum (Shanylis Pharmaceutical Limited, China), Compound tragacanth powder (William Ransom \& sons Limited, Hitchin Hetforshire, England), $R$. africana exudates, Benzoic acid BP (Hopkin \& Williams), Syrup BP, Orange oil (Halewood Chemicals Ltd, England), Chloroform water double strength, Propylene glycol, Ethanol (Philips Harris, England), Distilled water was prepared in our Laboratory in the Depatment of Pharmaceutics and Pharmaceutical Technology, Faculty of Pharmacy, University of Uyo, Nigeria).

\section{Methods}

\section{Collection, extraction and purification of $R$. africana gum}

The shoot and seeds of Raphia africana palm were collected from Nung Idio Ediene Ikono, Ikono Local Government Area of Akwa Ibom State and authenticated in the herbarium unit of the Faculty of Pharmacy, University of Uyo, Nigeria. The authentication voucher number is UUPH 8e (ii). The exudate of the plant was collected and then cleaned by removing the bark and other extraneous materials by hand-picking and dried in a hot air oven (Gallencamp, Germany) at $60{ }^{\circ} \mathrm{C}$ for about 24 hours until it became sufficiently brittle. The dried gum was processed by milling in a domestic blender into fine powder and labelled as unpurified $R$. africana gum. A quantity of $100 \mathrm{~g}$ of the crude $R$. africana gum was dissolved in $800 \mathrm{ml}$ of water and allowed to stand for about 20 hours with constant stirring. The gum mucilage was strained with calico cloth to remove insoluble debris and impurities and then precipitated with $580 \mathrm{ml}$ absolute alcohol. The precipitated gum was re-filtered and washed with $100 \mathrm{ml}$ of diethyl ether and dried in hot air oven (Gallencamp, Germany) for 24 hours (Akpabio et al., 2011). The dried gum was blended using a laboratory blender (Christison, United Kingdom) and screened through a sieve of $250 \mu \mathrm{m}$ aperture size. The powdered gum was used in subsequent tests and analyses as purified $R$. africana gum. The percentage yield was then calculated.

\section{Phytochemical screening}

Several tests as described by Evans (2009) were carried out on both raw and refined $R$. africana gum and their mucilage in order to determine the presence or absence of alkaloid, carbohydrate, combined anthraquinone (O-glycoside), free anthraquinone, and anthraquinone (C-glycoside).

\section{Organoleptic properties}

The taste, colour, odour and texture of both the raw and purified gums were observed using the appropriate sense organs and presented in Table I.

Table I: Organoleptic properties of $R$. africana gum

\begin{tabular}{cccc}
\hline Characteristics & Fresh gum & Solidified raw gum & Purified gum \\
\hline Colour & Milky & Brown & Brown \\
Odour & Characteristics & Characteristics & Odourless \\
Texture & Jelly-like & Solid mass & Fine powder \\
Taste & Sweet & Mucilaginous & Mucilaginous \\
\hline
\end{tabular}

\section{pH and moisture sorption capacity (MSC) of suspending agents}

A $2 \%$ dispersion of each suspending agent in distilled water was shaken for 5 minutes and the $\mathrm{pH}$ of its supernatant was determined in triplicate on a digital $\mathrm{pH}$ meter (Kent Industrial Measurements, United Kingdom) (Eraga et al., 2014).

Moisture sorption capacity (MSC) was determined gravimetrically as described by Lin and Chen, 2005. One gram (1 g) powder of each suspending agent $\left(\mathrm{M}_{\mathrm{d}}\right)$ was accurately weighed and evenly spread over the surface of a tarred petri dish lined with aluminum foil and placed in a desiccator containing distilled water (Relative Humidity $100 \%$ ) at $25 \pm 1{ }^{\circ} \mathrm{C}$. The sample was weighed 24 hourly until a constant weight was obtained on the $5^{\text {th }}$ day $\left(\mathrm{M}_{\mathrm{f}}\right)$. The percentage moisture uptake was determined using the equation below:

$$
\operatorname{MSC}=\left(\mathrm{M}_{\mathrm{f}}-\mathrm{M}_{\mathrm{d}}\right) / \mathrm{M}_{\mathrm{d}} \times 100 \% \quad \ldots \ldots \text { (1) }
$$

The values of both $\mathrm{pH}$ and MSC for all the polymers are presented in Table II.

Table II: Values of $\mathrm{pH}$ and moisture sorption capacity (MSC) of $R$. africana gum and other polymers:

\begin{tabular}{ccc}
\hline Suspending agents & pH & MSC (\%) \\
\hline$R$. africana gum & 6.70 & 2.5 \\
Compound tragacanth gum & 4.94 & 2.1 \\
Acacia gum & 4.73 & 3.8 \\
Gelatin & 6.38 & 2.5 \\
\hline
\end{tabular}

\section{Preparation of metronidazole suspension using different suspending agents}

Various batches of metronidazole suspension were prepared based on the formula presented in Table III. A quantity $(0.5 \mathrm{~g})$ of $R$. africana gum powder was weighed into a ceramic mortar and then triturated with $2 \mathrm{ml}$ of propylene glycol until a 
smooth paste was achieved. This was then triturated with $20 \mathrm{ml}$ of syrup BP, $2 \mathrm{ml}$ of benzoic acid solution and $2 \mathrm{ml}$ of orange oil were added gradually with constant stirring and then diluted with $50 \mathrm{mls}$ chloroform water double strength and mixed properly. The mixture was transferred into a $100 \mathrm{ml}$ measuring cylinder and distilled water was added to the $100 \mathrm{ml}$ mark and was shaken vigorously (thus making $0.5 \% \mathrm{w} / \mathrm{v}$ of the gum in the preparation). This procedure was repeated using $0.5 \% \mathrm{w} / \mathrm{v}, 1 \% \mathrm{w} / \mathrm{v}, 2 \% \mathrm{w} / \mathrm{v}, 3$ $\% \mathrm{w} / \mathrm{v}$ and $4 \% \mathrm{w} / \mathrm{v}$ of $R$. africana gum. These concentrations were also employed for compound tragacanth gum, acacia gum and gelatin in the preparation of different batches of metronidazole suspension. A batch containing no suspending agent $(0 \% \mathrm{w} / \mathrm{v})$ was also prepared.

Table III: Formula for preparation of metronidazole suspensions.

\begin{tabular}{ll}
\hline Ingredients & Quantity used \\
\hline Metronidazole powder & $4 \mathrm{~g}$ \\
Propylene glycol & $2 \mathrm{mls}$ \\
Benzoic acid solution & $2 \mathrm{mls}$ \\
Syrup BP & $20 \mathrm{mls}$ \\
Orange oil & $2 \mathrm{mls}$ \\
Chloroform water, double strength & $50 \mathrm{mls}$ \\
Suspending agent & $x(0-4 \% \mathrm{w} / \mathrm{v})$ \\
Water for preparation to & $100 \mathrm{mls}$ \\
\hline
\end{tabular}

\section{Sedimentation volume}

One hundred millilitres $(100 \mathrm{ml})$ of each suspension batch $\left(\mathrm{V}_{0}\right)$ was poured into a $100 \mathrm{ml}$ measuring cylinder and was left undisturbed for one week at room temperature. The ultimate volume of the sediment $\left(\mathrm{V}_{\mathrm{u}}\right)$ was taken at every hour for 7 hours and every 24 hours for 7 days. The sedimentation volume was calculated using the following equation:

$$
\mathrm{F}=\mathrm{V}_{0} / \mathrm{V}_{\mathrm{u}}
$$

\section{Redispersibility}

Redispersibility was assessed immediately after the last Sedimentation volume value was recorded by firmly sealing the mouth of the measuring cylinder and rotating the cylinder through $180^{\circ}$. The number of times the cylinder was rotated to achieve complete redispersion of the sediment of each sample was recorded as redispersibility number. The test was carried out in triplicate, that is at 7 days intervals (Okoye et al., 2014).

\section{Flow rate}

The time $\left(F_{t}\right)$ in seconds, required for a quantity of each suspension sample to flow through $10 \mathrm{ml}$ pipette $\left(\mathrm{F}_{\mathrm{v}}\right)$ was determined in triplicate. Flow rate $(\mathrm{ml} / \mathrm{s})$ also referred to as apparent viscosity (Sudam et al., 2012) was then computed as the ratio of $F_{v}$ to $F_{t}$. The value recorded was the average of three determinations.

\section{Viscosity}

The viscosity of each suspension batch was measured using Brookfield digital viscometer (Model Number NDJ-5s) at 60 revolutions per minutes using spindle number 2 . About $50 \mathrm{ml}$ of each sample was placed in the viscometer beaker and the instrument then switched on. The instrument measures the viscosity traction on the spindle rotating in the sample. The parameter was determined in triplicate and the average value was recorded for each sample.

\section{Particle size}

The particle size distribution of each batch of the suspensions was determined using an optical microscope (Olympus Optical Co., Japan). A drop of well shaken suspension from each batch was separately smeared on the microscope slide and viewed at x 100 magnification. The particle diameter $(\mathrm{X})$ was carefully measured and recorded for 300 particles $(\mathrm{N})$. The average particle diameter, $d$ was then calculated for each batch:

$$
d=\Sigma \mathrm{N} . \mathrm{X} / \mathrm{N}
$$

\section{Degree of flocculation}

To each suspension sample, Potassium dihydrogen phosphate was added as a deflocculating agent. The degree of flocculation $(\beta)$ was determined as the ratio of the sedimentation volume of flocculated suspension (in formulations in which no deflocculating agent was added) (F) to that of deflocculated suspension ( $\mathrm{F} \alpha)$ (Sudam et al., 2012, Singh et al., 2013):

$$
\beta=\mathrm{F} / \mathrm{F} \alpha
$$

\section{Statistical analysis}

SPSS statistical package was employed for statistical analysis. Mean and standard deviations for all the data were computed. The student's t-test was used to determine statistically significant differences at $\mathrm{p}<0.05$, for comparison of batches.

\section{RESULTS AND DISCUSSION}

The exudates gotten from $R$. africana gave a yield of $30.4 \% \mathrm{w} / \mathrm{w}$ of pure gum. The results of the organoleptic properties determined for fresh, solidified raw and purified forms of $R$. africana gum presented in Table I indicates that the organoleptic characteristics the gum would exhibit is a function of its physical state. Phytochemical screening carried out on $R$. africana gum showed absence of alkaloid, carbohydrate and anthraquinones, implying that the material is somewhat inert. Also, it confirms the belief that hydrocolloids are devoid of carbohydrates, but complex acids built up of less common sugar (Femi-Oyewo et al., 2004). The values of $\mathrm{pH}$ and moisture sorption capacity for all the suspending agents studied are presented in Table II. All the polymers exhibited weakly acidic $\mathrm{pH}$, hence, in liquid delivery systems, they are expected to be compatible with active pharmaceutical ingredients that has $\mathrm{pH}$ values within this range. Determination of this parameter thus, $a b$ initio, ascertains that the experimental suspending agent would not hinder the therapeutic activity as well as stability of the drug in the formulation (Lira Suares et al., 2005). Very low values of moisture sorption capacity of the tested materials indicates their stability under humid condition $(100 \% \mathrm{RH})$. The lower the value, the lower is the 
tendency of moisture sensitive drug components of a formulation to undergo hydrolytic degradation. Statistically, there is no significant difference between the MSC values for all the suspending agents ( $\mathrm{p}>0.05)$.

The suspending tendency of the tested polymers in metronidazole suspension formulations were evaluated with respect to their sedimentation volume, redispersibility, flow rate, viscosity, degree of flocculation and particle size. As presented in Table IV, and in typical plots of Sedimentation volume, F against concentration, and against time (Figures 1 and 2, respectively), the values of $\mathrm{F}$ for all formulations were observed to increase as concentration of the suspending agents increased. Conversely, the values decreased as the storage time increased but remained constant after day 3. Generally, at all concentrations, suspensions formulated with $R$. africana gum exhibited higher values of $\mathrm{F}$ than those containing other polymers. A good suspension should exhibit ready redispersibility (that is low redispersibility number) so as to ensure uniformity of administered doses of medicament upon shaking (Bhurat et al., 2012). All the formulations exhibited low redispersibility number as shown in Table V.

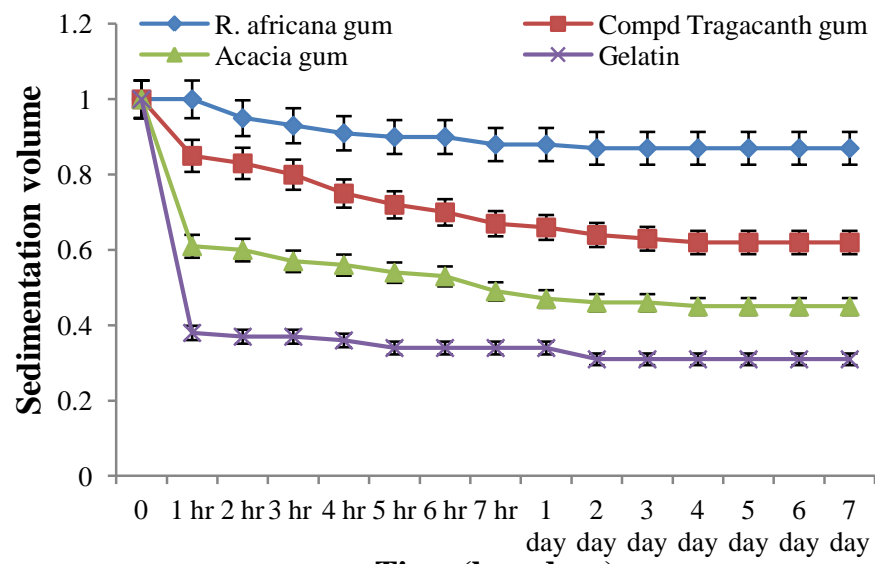

Time (hrs, days)

Fig 1: Plots of sedimentation volume of metronidazole suspension against time (hours and days) at $4 \%$ concentration.

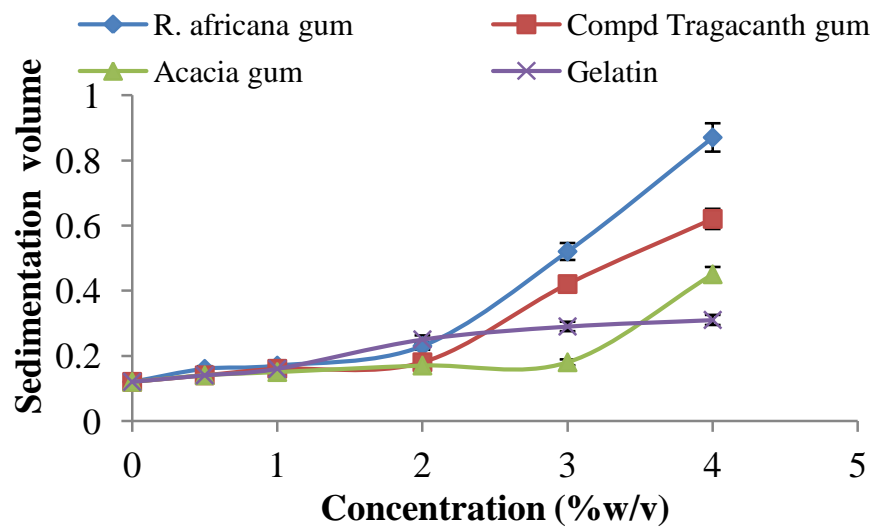

Fig. 2: plots of sedimentation volume of metronidazole suspension against concentration $(\% \mathrm{w} / \mathrm{v})$ on day 7.

Typical plots of flow rate of suspension against concentration of suspendants (Figure 3) and the values included in
Table $\mathrm{V}$ indicate that the former parameter reduces as the latter increases. The optimum viscosity is of paramount importance for stability and pourability of suspension formulation. The optimum concentration of the suspending agent imparting thickening on the suspension has to be identified such that the stability is maintained alongside its dispensability. In this investigation, viscosity increase with increase in concentration of suspendants (Table $\mathrm{V}$ and Figure 4). It should be noted that, at $4 \%$ concentration, $R$. africana gum was too viscous and as such, Redispersibility number, flow rate and viscosity could not be determined. This implies that the gum is more economical than other tested polymers because logically, the applicable proportion as suspending agent should not exceed 3.0 $\%$.

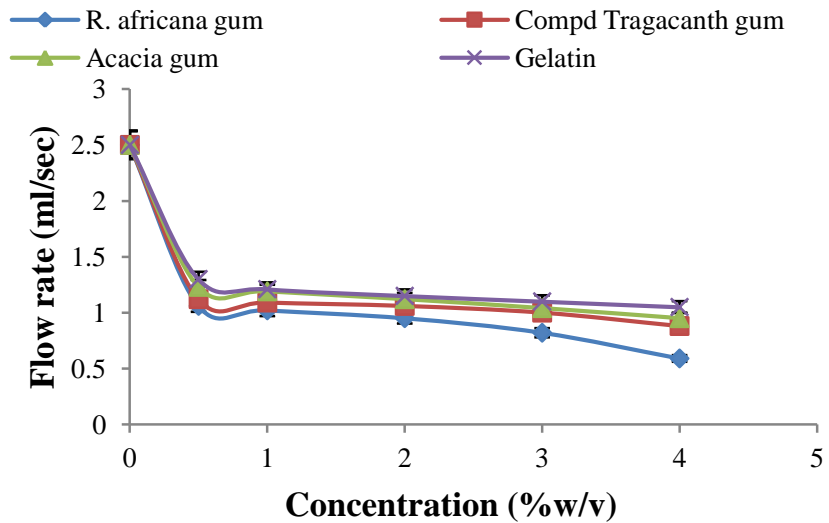

Fig. 3: Plots of flow rate of metronidazole suspensions versus concentration of suspending agents at $25^{\circ} \mathrm{C}$.

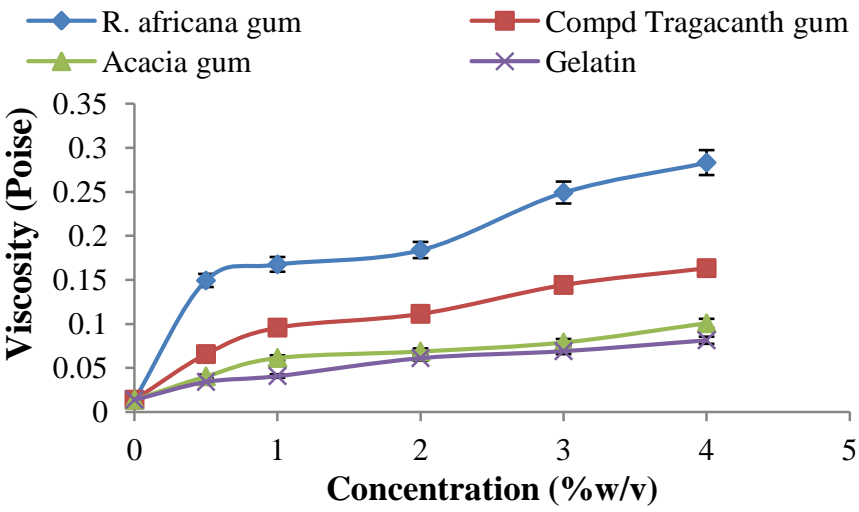

Fig. 4: Plots of viscosity of metronidazole suspensions versus concentration of suspending agents at $25^{\circ} \mathrm{C}$.

Since Sedimentation volume gives only a qualitative assessment of flocculation (Martin et al., 1993), the degree of flocculation $(\beta)$ is more important parameter in pharmaceutical suspensions (Sudam et al., 2012). The degree of flocculation as presented in Table $\mathrm{V}$ follows the same direct relationship with concentration of suspending agent as observed for sedimentation volume. Incorporation of deflocculating agent probably reduced the tight packing behaviour of all the suspending agents as observed by Oppong et al. (2016). This effect diminished as the concentration increased, thus leading to progressive increase in the degree of flocculation. 
Table IV: Sedimentation volume of metronidazole suspensions containing various concentrations of the suspending agents.

\begin{tabular}{|c|c|c|c|c|c|c|c|c|c|c|c|c|c|c|c|c|}
\hline \multirow{4}{*}{ Type of suspending agents } & \multirow[t]{4}{*}{ Conc. } & \multicolumn{15}{|c|}{ Sedimentation volume } \\
\hline & & \multicolumn{15}{|c|}{ Time } \\
\hline & & \multicolumn{8}{|c|}{ Hours } & \multicolumn{7}{|c|}{ Days } \\
\hline & & $\mathbf{0}$ & 1 & 2 & 3 & 4 & 5 & 6 & 7 & 1 & 2 & 3 & 4 & 5 & 6 & 7 \\
\hline \multirow{6}{*}{ Raphia africana gum } & 0.0 & 1.00 & 0.18 & 0.17 & 0.15 & 0.15 & 0.15 & 0.15 & 0.15 & 0.13 & 0.12 & 0.12 & 0.12 & 0.12 & 0.12 & 0.12 \\
\hline & 0.5 & 1.00 & 0.32 & 0.30 & 0.23 & 0.21 & 0.20 & 0.18 & 0.17 & 0.17 & 0.17 & 0.16 & 0.16 & 0.16 & 0.16 & 0.16 \\
\hline & 1.0 & 1.00 & 0.35 & 0.32 & 0.24 & 0.22 & 0.22 & 0.20 & 0.20 & 0.18 & 0.18 & 0.17 & 0.17 & 0.17 & 0.17 & 0.17 \\
\hline & 2.0 & 1.00 & 0.46 & 0.43 & 0.38 & 0.35 & 0.34 & 0.30 & 0.28 & 0.25 & 0.25 & 0.24 & 0.24 & 0.23 & 0.23 & 0.23 \\
\hline & 3.0 & 1.00 & 0.68 & 0.65 & 0.63 & 0.63 & 0.62 & 0.62 & 0.60 & 0.57 & 0.56 & 0.54 & 0.53 & 0.52 & 0.52 & 0.52 \\
\hline & 4.0 & 1.00 & 1.00 & 0.95 & 0.93 & 0.91 & 0.90 & 0.90 & 0.88 & 0.88 & 0.87 & 0.87 & 0.87 & 0.87 & 0.87 & 0.87 \\
\hline \multirow{5}{*}{ Comp.Tragacanth gum } & 0.5 & 1.00 & 0.30 & 0.27 & 0.22 & 0.19 & 0.18 & 0.17 & 0.17 & 0.16 & 0.16 & 0.15 & 0.14 & 0.14 & 0.14 & 0.14 \\
\hline & 1.0 & 1.00 & 0.34 & 0.32 & 0.26 & 0.23 & 0.21 & 0.19 & 0.19 & 0.18 & 0.18 & 0.17 & 0.16 & 0.16 & 0.16 & 0.16 \\
\hline & 2.0 & 1.00 & 0.4 & 0.36 & 0.31 & 0.28 & 0.26 & 0.23 & 0.20 & 0.19 & 0.19 & 0.19 & 0.18 & 0.18 & 0.18 & 0.18 \\
\hline & 3.0 & 1.00 & 0.58 & 0.55 & 0.54 & 0.52 & 0.52 & 0.48 & 0.46 & 0.44 & 0.43 & 0.43 & 0.42 & 0.42 & 0.42 & 0.42 \\
\hline & 4.0 & 1.00 & 0.85 & 0.83 & 0.80 & 0.75 & 0.72 & 0.70 & 0.67 & 0.66 & 0.64 & 0.63 & 0.62 & 0.62 & 0.62 & 0.62 \\
\hline \multirow{5}{*}{ Acacia gum } & 0.5 & 1.00 & 0.19 & 0.18 & 0.18 & 0.17 & 0.17 & 0.16 & 0.16 & 0.15 & 0.15 & 0.14 & 0.14 & 0.14 & 0.14 & 0.14 \\
\hline & 1.0 & 1.00 & 0.26 & 0.20 & 0.20 & 0.19 & 0.19 & 0.18 & 0.17 & 0.16 & 0.16 & 0.15 & 0.15 & 0.15 & 0.15 & 0.15 \\
\hline & 2.0 & 1.00 & 0.39 & 0.35 & 0.24 & 0.22 & 0.20 & 0.18 & 0.18 & 0.17 & 0.17 & 0.17 & 0.17 & 0.17 & 0.17 & 0.17 \\
\hline & 3.0 & 1.00 & 0.42 & 0.36 & 0.26 & 0.23 & 0.22 & 0.22 & 0.20 & 0.19 & 0.19 & 0.18 & 0.18 & 0.18 & 0.18 & 0.18 \\
\hline & 4.0 & 1.00 & 0.61 & 0.60 & 0.57 & 0.56 & 0.54 & 0.53 & 0.49 & 0.47 & 0.46 & 0.46 & 0.45 & 0.45 & 0.45 & 0.45 \\
\hline \multirow{5}{*}{ Gelatin } & 0.5 & 1.00 & 0.20 & 0.19 & 0.18 & 0.18 & 0.17 & 0.16 & 0.16 & 0.16 & 0.15 & 0.15 & 0.15 & 0.15 & 0.14 & 0.14 \\
\hline & 1.0 & 1.00 & 0.22 & 0.20 & 0.20 & 0.20 & 0.20 & 0.18 & 0.18 & 0.18 & 0.16 & 0.16 & 0.16 & 0.16 & 0.16 & 0.16 \\
\hline & 2.0 & 1.00 & 0.30 & 0.28 & 0.26 & 0.26 & 0.26 & 0.26 & 0.26 & 0.25 & 0.25 & 0.25 & 0.25 & 0.25 & 0.25 & 0.25 \\
\hline & 3.0 & 1.00 & 0.34 & 0.32 & 0.32 & 0.32 & 0.30 & 0.30 & 0.30 & 0.30 & 0.29 & 0.29 & 0.29 & 0.29 & 0.29 & 0.29 \\
\hline & 4.0 & 1.00 & 0.38 & 0.37 & 0.37 & 0.36 & 0.34 & 0.34 & 0.34 & 0.34 & 0.31 & 0.31 & 0.31 & 0.31 & 0.31 & 0.31 \\
\hline
\end{tabular}

Table V: Rheological properties of metronidazole suspensios formulated with different suspending agents at different concentrations.

\begin{tabular}{|c|c|c|c|c|c|c|}
\hline $\begin{array}{c}\text { Suspending } \\
\text { agents }\end{array}$ & $\begin{array}{c}\text { Concentration } \\
(\% \mathrm{w} / \mathrm{v})\end{array}$ & $\begin{array}{c}\text { Redispersibility } \\
\text { number }\end{array}$ & $\begin{array}{c}\text { Flow rate } \\
(\mathrm{ml} / \mathrm{sec})\end{array}$ & $\begin{array}{c}\text { Viscosity at } 25^{0} \mathrm{C} \\
\text { (poise) }\end{array}$ & $\begin{array}{c}\text { Degree of } \\
\text { flocculation }\end{array}$ & $\begin{array}{c}\text { Mean particle diameter } \\
d(\mu \mathrm{m})\end{array}$ \\
\hline \multirow{6}{*}{ R. africana gum } & 0.0 & 5.33 & 2.5 & 0.25 & 0.75 & 1.85 \\
\hline & 0.5 & 7.00 & 1.06 & 0.85 & 1.40 & 1.50 \\
\hline & 1.0 & 9.67 & 1.02 & 1.30 & 1.72 & 1.68 \\
\hline & 2.0 & 11.33 & 0.95 & 2.05 & 2.07 & 1.85 \\
\hline & 3.0 & 13.00 & 0.82 & 2.30 & 2.28 & 1.90 \\
\hline & 4.0 & \multicolumn{3}{|c|}{ Too viscous to be determined } & 2.55 & 2.05 \\
\hline \multirow{5}{*}{$\begin{array}{l}\text { Compound } \\
\text { tragacanth gum }\end{array}$} & 0.5 & 6.00 & 1.12 & 0.70 & 1.05 & 1.80 \\
\hline & 1.0 & 7.67 & 1.09 & 1.15 & 1.21 & 1.95 \\
\hline & 2.0 & 8.00 & 1.06 & 1.55 & 1.53 & 2.04 \\
\hline & 3.0 & 9.33 & 1.00 & 1.80 & 1.73 & 2.30 \\
\hline & 4.0 & 10.67 & 0.88 & 2.15 & 1.90 & 2.32 \\
\hline \multirow{5}{*}{ Acacia gum } & 0.5 & 5.67 & 1.23 & 0.65 & 1.02 & 1.75 \\
\hline & 1.0 & 7.33 & 1.19 & 1.05 & 1.17 & 1.88 \\
\hline & 2.0 & 8.67 & 1.12 & 1.45 & 1.38 & 1.99 \\
\hline & 3.0 & 9.00 & 1.04 & 1.70 & 1.44 & 2.11 \\
\hline & 4.0 & 9.67 & 0.95 & 1.85 & 1.57 & 2.18 \\
\hline \multirow{5}{*}{ Gelatin } & 0.5 & 5.33 & 1.30 & 0.45 & 0.90 & 2.05 \\
\hline & 1.0 & 6.33 & 1.21 & 0.75 & 0.97 & 2.10 \\
\hline & 2.0 & 7.00 & 1.15 & 0.90 & 1.05 & 2.37 \\
\hline & 3.0 & 8.33 & 1.10 & 1.25 & 1.14 & 2.75 \\
\hline & 4.0 & 9.00 & 1.05 & 1.55 & 1.20 & 3.02 \\
\hline
\end{tabular}

The average particle diameter values of dispersed phase for all the suspensions were generally low - less than $5 \mu \mathrm{m}$ (Table V) which may promote the physical stability of the formulations (Singh et al., 2013) as can be deduced from Stoke's expression [(particle size, $d$ is a direct function of the distance of fall of the particle, $h$ per unit time $t(h / t)$ (Femi-Oyewo et al., 2004)]

The results summarily show that inverse relationship was observed between concentration of suspendants and flow rate while direct proportionality existed between them and other parameters - sedimentation volume, dispersibility number, degree of flocculation, viscosity and particle size. Statistically, $R$. africana gum exhibited significantly lower flow rate $(\mathrm{p}<0.05)$ and higher values of other parameters $(\mathrm{p}<0.05)$ than other tested suspendants.

Based on these assessed paramneters, the effectiveness of the tested suspending agents can be ranked as follows: $R$. africana gum > Compound Tragacanth gum > Acacia gum > gelatin. 


\section{CONCLUSSION}

The relative cheapness, non-toxicity, biocompatibility and biodegradability of $R$. africana hydrocolloid made it a better candidate as suspending agent than other investigated natural polymers. This work shows that from the assessment of all the suspensions formulated with various natural polymers, $R$. africana hydrocolloid exhibited the best suspendability indices and can thus be developed as excipient in pharmaceutical suspension formulations. Also, due to its high viscosity, its mucilage may be used as thickening and stabilizing agents in pharmaceutical as well as food and cosmetic industries even at lower concentrations than other examined polymers.

\section{Financial support and sponsorship: Nil.}

Conflict of Interests: There are no conflicts of interest.

\section{REFERENCES}

Adikwu MU, Yoshikawa Y, Takada K. Bioadhesive delivery of metformin using prosopis gum with antidiabetic potential. Biol Pharm Bulletin, 2003; 26 (5): $662-666$.

Akpabio E, Jackson C, Ubulom P, Adedokun M, Umoh R, Ugwu C. Formulation and in vitro release properties of a plant gum obtained from sesamum indicum (Fam. pedaliaceae). Int J Pharm Biomed Res, 2011; 2 (3): 166-171

Ali Y, Kimura A, Martin J. Coffey MJ, Tyle P. 2010. Pharmaceutical Development of Suspension Dosage Form. In: Kulshreshtha AK et al, eds. Pharmaceutical Suspensions: From Formulation Development to Manufacturing, New York: Springer 104.

Ansel C, Allen LV, Popovich NG. 2005. Disperse systems: Pharmaceutical Dosage Forms and Drug Delivery Systems 8th ed, Philadelphia: Lippincott Williams and Wilkins 387-389, 398.

Bhurat MR, Kawatikwar PS, Sanghavi RS, Patil PP, Salunke PA, Kapure SV. Evaluation of Eulophia herbacea tubers mucilage as an innovative suspending agent. J Pharm Res, 2012; 5 (1): 321-323

Eraga SO, Iwuagwu MA, Adikwu MU. Evaluation of the Suspending Properties of the Coprecipitate of Irvingia gabonesis Gum and Gelatin. Trop J Pharm Res, 2014; 13 (6): 843-848

Evans WC 2009. Trease and Evans Pharmacognosy, 16th Ed. Saunders Elsevier, 135-149.

Femi-Oyewo MN, Adedokun MO, Olusoga TO. Evaluation of the suspending properties of Albizia gum on sulphadimidine suspension. Trop J Pharm Res, 2004; 3 (1): 279-284.

Lin YC, Chen X. Moisture sorption desorption characteristics and its effect on the mechanical behavior of the epoxy system. Polymer, 2005; 46 (5): 11994-12003

Lira Soares LA, Ortega GG, Petrovick PR, Schmidt PC. Dry granulation and compression of spray-dried plant extracts. AAPS Pharm Sci Tech, 2005; 6 (3): E359-66
Mahmud HS, Oyi AR, Allagh TS. Evaluation of the suspending property of Khaya senegalensis gum in formulation of paracetamol suspension. Nig J Pharm Sci, 2009; 8 (1): 128 - 134.

Majekodunmi SO, Itiola OA. Physicochemical and binding properties of Raphia africana gum in paracetamol tablet formulations. Aca J Biotechnol, 2016; 4 (5): 177-185.

Martin A, Swarbrick J, Cammarata A. 1993. Physical Pharmacy 4th ed. Philadelphia and London: Lea and Febiger 477-511.

Nash TE. Treatment of Giardia lamblia . Paed Infect Dis J, 2001; 20: 193-195.

Obahiagbon FI. A review of the origin, morphology, cultivation, economic products, health and physiological implications of Raphia palm. Afr J Food Sci, 2009; 3 (13): 447-453

Okoye E, Edochie C, Adegbemi JO. Preliminary evaluation of Delonix regia seed gum as a suspending agent in a liquid oral dosage form. Int J Pharm Sci Drug Res, 2014; 6(2): 114-119

Olorunsola EO, Bhatia PG, Tytler BA, Adikwu MU. Surface activity and hydrophile-lipophile balance of hydrophilic polymers from exudates of cashew and khaya plants. Int J Pharm Biol Res, 2014; 5 (5): 443-448.

Olorunsola EO, Adedokun MO. Surface activity as basis for pharmaceutical applications of hydrocolloids: A review. J App Pharm Sci, 2014; 4 (10): 110-116

Oppong EE, Osei-Asare C, Klu, MW. Evaluation of the suspending properties of shea tree gum. Int J Pharm Pharm Sci, 2016; 8 (7): 409-413

Otedoh, J. Raphia Africana. Nig Inst Oil Palm Res, 1982; 6 (22): 156.

Singh I, Singh A, Thakur G, Odeku OA. Assessment of Suspending Properties of Katira Gum: Formulation and Evaluation of Nimesulide Suspension Journal of Pharmaceutical Technology, Research and Management, 2013; 1 (2): 205-215

Stanley SL Jr. Amoebiasis. Lancet, 2003; 361: 1025-1034.

Sudam N, Manish B, Ritesh M, Sachin P, Ratnaparkhi MP, Shilpa C. Evaluation of various natural suspending agents for its suspending behaviour using paracetamol as model drug for suspension. Asian J Pharm Cli Res, 2012; 5 (4): 183-186

The United States Pharmacopoeia / National Formulary, USP 37 / NF 32, Vol. I. The United States Pharmacopoeial Convention, Timbrook Parkway, Rockville: 2014, 342-344, 487, 1146.

\section{How to cite this article:}

Adedokun MO, Olorunsola EO, Anselem EL. Comparative Evaluation of Metronidazole Suspensions Formulated with Raphia africana Hydrocolloid and other Natural Polymers. J App Pharm Sci, 2017; 7 (06): 121-126. 